urging universities and industrial and government research establishments to work morc closely together when they see what has happened at Reading? It is quite obvious that if the Government refuses to allow a Tropical Research Institute to be built there, it will not be built anywhere.

\section{Tropical Pests}

Every research unit set up to solve a specific problem learns that the more successful it is, the less it justifies its continued existence. Inevitably it must face diversification or dissolution. The Anti-Locust Research Centre of the Ministry of Overseas Development is coming close to this stage in its development and has rightly begun work on other pests besides locusts. Of course, the real answer would be for the centre to become part of a larger Tropical Research Institute, but plans for that seem to have been scotched for the time being (see page 625 ).

The British Government's interest in locust control began in 1930 with the establishment of a Locust Subcommittee to consider how to prevent a repetition of the widespread plagues of desert locusts which occurred in British East Africa in 1929. The Anti-Locust Research Centre, which was established in 1945, grew out of this decision and the work of Sir Boris Uvarov at the old Imperial Bureau of Entomology. Since 1945 the centre has steadily expanded, and this year, as it puts down roots on the second floor of the building in which it is housed, its budget from the ministry is $£ 231,000$ and it has also received $\$ 20,000$ from the FAO for running the Desert Locust Information Service and other sums for specific research contracts.

As a result of work at the centre and in the field in the member countries of the International African Migratory and Red Locust Control Services, both the red and migratory locusts, which breed in flood plain grassland in East Africa and in Mali and Niger respectively now seem to be well under control. The desert locust, however, could still present a threat. Biogeographers at the research centre, who under the auspices of the FAO are responsible for the Desert Locust Information Service, are currently mapping outbreaks of this species which this year has shown some signs of resurgence in Arabia and along the Red Sea coastline. But so long as the present methods of control are in fact used they are confident that the swarms can be controlled before they reach plague levels.

Now that pesticides have brought the red, migratory and desert locusts more or less under control, the policy of the centre is shifting. Predictably the centre is becoming increasingly interested in locust pheromones and grass attractants with the obvious long term aim of finding some method of biological control. As far as locusts are concerned, of course, the classical method of releasing predators is useless because the locusts migrate. The centre is also beginning to look at other tropical insect pests. As a start it has begun working on the behaviour and biology of the army worm moth-a pest of grain crops-in a joint project with the East African Agriculture and Forestry Research Organization. The army worm moth was selected because many of its behaviour patterns resemble those of locusts and the centre can justly claim as one of its fundamental policies that no control is begun until the biology of the pest is known. That is basic common- sense, of course, because until the biology is known it is impossible to decide where and what to control. But self-evident though it may sound, it is often in practice ignored, and that is one of the reasons why the centre is also starting work in a small way on a bird, the Quelea, which is a pest of grain crops such as millet in much of southern Africa. The behaviour of this finch-like bird again has striking similarities to that of locusts, so much so, in fact, that it has been called a feathered locust, and the present control methods are proving to be quite ineffective. At the moment in South Africa and Nigeria, for example, the birds are poisoned or blasted. But the sledgehammer is not cracking the walnut, and even though a hundred million Quelea were killed in South Africa alone last year they are as much a pest as ever. One scientist at the centre, with previous experience of Quelea control in Nigeria, is going to Africa to try to find exactly how the bird's feeding behaviour is related to the cycle of harvest of its natural food, wild grasses and grain crops such as millet. It seems that when offered the choice the birds prefer their natural food, and oddly enough Botswana farmers appear to have accidentally hit on a way of reducing the damage caused by Quelea by synchronizing their harvest with the time of natural grass seeding.

These other pests admittedly do not share the emotive appeal, full of biblical overtones, of plagues of locusts, but they present more or less identical problems of control, and, like the locusts, they cause intensive but localized destruction. None of them is likely to upset a national economy, but they all cause acute local hardship.

\section{Diseases in the Wild}

In his introduction at the symposium on diseases in free living wild animals held at the Zoological Society on May 9 and 10, Sir Zolly Zuckerman remarked that this is a subject of particular interest to the Zoo, where animals rarely arrive free from disease. The animals bring with them from the wild viruses, bacteria and various parasites, although they do not always show symptoms of the diseases for which these organisms are responsible. There are other reasons for studying diseases in wild animals, for there is always the possibility that epidemics might seriously deplete supplies of game or spread to man and his domestic stock. The symposium brought together much of the contemporary knowledge of this subject, and will be published later by the Zoological Society.

A survey of the incidence of foot and mouth disease in Rhodesia was described by Dr J. B. Brooksby, director of the Animal Virus Research Unit at Pirbright. Immunological tests have shown that foot and mouth disease virus is carried by buffalo, impala and kudu-which show the highest antibody titres and also frequent symptoms of the disease--as well as by eland, wildebeeste and various other wild animals. Strains of the viruses seem to be adapted to particular host species, but new strains sometimes develop which break out and cause an epizootic. Although more data are required about transmission between wild and domestic stock, it seems that in areas where there are abundant. wild animals which come into close contact with domestic stock, there is some danger of the disease spreading to the latter. In South Africa in 1962, for 